\title{
Sacralización, ritualización y espectáculo en torno al pasado: EI Museo de la Memoria y los Derechos Humanos en Chile ${ }^{1}$
}

\section{Resumen}

El objetivo de este artículo es desarrollar una reflexión crítica acerca del proceso de inscripción pública de la memoria (traumática) en América Latina. A partir de un caso concreto, el Museo de la Memoria y los Derechos Humanos de Chile, proponemos explorar los procesos de sacralización realizados en el interior de esta institución y analizar el rol del Museo en la legitimación de una narrativa.

El objetivo es mostrar cómo todo proceso de materialización institucional del recuerdo conlleva no solo la elección de un relato sino, sobre todo, el intento de oficialización de un discurso (imaginado) sobre el pasado. El resultado es un espacio destinado a la celebración del culto a la memoria, un lugar cargado de prácticas ritualizadas que expulsan de la institución todo lo que desafía al orden consagrado, todo lo que promueve el escepticismo.

Palabras clave: Chile, memoria, museo, dictadura.

Referencia para citar este artículo: SÁNCHEZ DEL OLMO, Sara (2016). "Sacralización, ritualización y espectáculo en torno al pasado: El Museo de la Memoria y los Derechos Humanos en Chile". En Anuario de Historia Regional y de las Fronteras. 21 (2). pp. 193-216.

Sara Sánchez del Olmo: Doctora en Historia de América, Universidad de Valladolid, España. Magíster en Estudios Amerindios, Universidad Complutense de Madrid, España. Licenciada en Filosofía y Letras, Universidad de Valladolid, España. Investigadora asociada del Instituto Religiones, Culturas, Modernidad (IRCM), Universidad de Lausana (Suiza). Correo electrónico: Sara.SanchezDelOlmo@ne.ch.

\footnotetext{
1 Este artículo forma parte del proyecto de investigación Vitrines du sacrifice: dimensions symbolicorituelles et sacralisation du passé aux Musées de la Mémoire en Amérique Latine, financiado gracias a la beca postdoctoral Mary Douglas de la Facultad de Teología y Ciencias de las Religiones de la Universidad de Lausana (Suiza).
} 


\title{
Sacralization, Ritualization and Entertainment Around the Past: The Museo de la Memoria y los Derechos Humanos in Chile
}

\begin{abstract}
The aim of this paper is to develop a critical reflection on the process of public recording of the (traumatic) memory in Latin America. From a specific case, the Museo de la Memoria y los Derechos Humanos in Chile; We intend to explore the sacralization processes made within this institution and analyze the role of the Museum in legitimizing a narrative.

Our goal is to show how any institutional materialization process of remembrance involves not only the choice of a story but, above all, the attempt to give official recognition to an (imagined) speech about the past. The result is a space for the celebration of the cult of memory, a place full of ritualized practices that expel from the institution everything that defies the enshrined order, and everything that promotes skepticism.
\end{abstract}

Keywords: Chile, Memory, Museum, Dictatorship.

\section{Sacralização, ritualização e espetáculo em torno ao passado: O Museo de la Memoria y los Derechos Humanos em Chile}

\section{Resumo}

O objetivo deste artigo é desenvolver uma reflexão sobre o processo de inscrição pública da memória (traumática) na América Latina. A partir de um caso concreto, $o$ Museo de la Memoria y los Derechos Humanos do Chile, propomo-nos explorar os processos de sacralização realizados ao interior desta instituição e analisar o papel do Museu na legitimação de uma narrativa.

Nosso objetivo é mostrar como todo processo de materialização institucional da lembrança leva não apenas à eleição de um relato, mas principalmente, a tentativa de oficialização de um discurso (imaginado) sobre o passado. O resultado é um espaço destinado à celebração do culto à memória, um lugar carregado de práticas ritualizadas que expelem da instituição tudo o que desafia a ordem consagrada, tudo o que promove o cepticismo.

Palavras chave: Chile, memória, museu, ditadura. 


\section{Introducción}

El interés por la memoria ha cobrado en los últimos decenios dimensiones estratosféricas. Como bien ha señalado Alon Confino, "[...] the notion of 'memory' has taken its place now like as a leading term, recently perharps the leading term, in cultural history"2. La memoria, término polisémico y particularmente complejo, se ha convertido en una categoría metahistórica e, incluso, teleológica. Convertida en sujeto privilegiado de análisis y reivindicaciones, su éxito, su exaltación y su propagación coinciden con un tiempo (desilusionado y precario) en el que el pasado no proporciona ya las respuestas y el futuro parece no ofrecer expectativas. La memoria es parcial, alusiva, fragmentaria y efímera ${ }^{3}$. No es extraño pues que sea el modo de discurso típico de la condición postmoderna ${ }^{4}$.

Esta inusitada atención por la memoria, nacida según Andreas Huyssen en la década de los sesenta, se transforma a comienzos de la década de los ochenta en una obsesión: la activación del debate en torno al genocidio judío y la profusión de aniversarios y recordatorios provocan una explosión memorial marcada por la dimensión totalizadora del discurso del Holocausto. A partir de ese momento, esta queda convertida en el tropo universal del trauma histórico ${ }^{5}$.

El carácter colectivo de los múltiples sucesos dramáticos ocurridos a lo largo del siglo XX ha provocado que sus efectos se registren aún varias generaciones después de ocurridos los hechos, inscribiéndose -como señala LaCapra- en un ciclo de repeticiones. De esta manera, las heridas no cerradas han forjado un tipo de memoria particular que más que memoria de los acontecimientos es, ante todo, memoria de los sufrimientos y de las atrocidades, memoria traumática ${ }^{6}$.

2 Confino, Alon. "Collective Memory and Cultural History: Problems of Method", en The American Historical Review, vol. 102, núm. 5 Chicago, University of Chicago Press, 1997, pp. 1386-1403.

3 Klein, Kerwin Lee. From History to Theory (Berkeley and Los Angeles: University of California Press, 2011), p. 127.

4 El fenómeno, como bien ha señalado Pécaut, se enmarca dentro del desmoronamiento del Estado-nación tanto en el plano concreto como simbólico. Pécaut, Daniel. "Memoria imposible, historia imposible, olvido imposible”, en Belay, Raynald; Bracamont, Jorge; Degregori, Carlos Iván y Vacher, Jean Joinville (Dirs.), Memorias en conflicto, Aspectos de la violencia política contemporánea (Lima: IEP-IFEA, 2004), pp. 87104. Su omnipresencia está también estrechamente vinculada a una crisis de la transmisión, a una profunda transformación de la experiencia del tiempo y, sobre todo, de la relación del ser humano con la historia. Sobre la transformación de la experiencia del tiempo: Hartog, François. Régimes de historicité. Présentisme et expériences du temps (Paris: Éditions du Seuil, 2012).

5 Huyssen, Andreas. En busca del futuro perdido. Cultura y memoria en tiempos de globalización (Buenos Aires: Fondo de Cultura Económica, 2001), pp. 15-17.

6 Las memorias traumáticas pueden definirse como recuerdos sobre hechos con una valencia negativa y un alto impacto emocional. El impacto que los hechos traumáticos tienen sobre las personas depende de factores muy diversos, y hay fuertes diferencias individuales que determinan la experiencia fenomenológica asociada al recuerdo del suceso vivido. Se encuentra así frente a la re-experimentación, la evitación y la hiperactivación. Manzanero, A. L. y Recio, M. "El recuerdo de hechos traumáticos: exactitud, tipos y características", en Cuadernos de Medicina Forense, vol. XVIII, núm. 1, Málaga, Asociación de Médicos Forenses de Andalucía, 2012, pp. 19-25. http://scielo.isciii.es/scielo.php?script=sci_arttext\&pid $=$ S1135-76062012000100003 (4 de mayo del 2015). 
Por otro lado, en un tiempo marcado por la angustia derivada de la velocidad del cambio, por el temor hacia un futuro que parece no ofrecer expectativas, por la inestabilidad colectiva derivada de una profunda transformación de la experiencia del tiempo, uno de los grandes temores es, precisamente, el olvido. Para hacer frente a ese miedo, para compensar la pérdida de identidad que la acecha, para combatir su propia fragilidad, la sociedad postmoderna se ha lanzado a un irrefrenable proceso de almacenamiento y conservación de la memoria. Su inscripción pública (especialmente de la memoria traumática) se ha convertido así en un asunto de capital importancia. El resultado no es otro que la multiplicación de espacios conmemorativos en los que se escenifican los dramas de un pasado que se niega a pasar.

Entre todos ellos se destaca, sin duda, el museo, el cual es convertido en uno de los lugares predilectos para conjurar la pérdida. En él se crea, se condensa, se cristaliza, se refugia, se ideologiza, se expresa y se trasmite la memoria. También es, en ocasiones, el lugar donde la memoria es deliberadamente ocultada. Por todo ello, el museo constituye un privilegiado instrumento para explorar los procesos de preservación y trasmisión de la misma.

El análisis de la transformación de la memoria (traumática) en discurso museográfico permite observar cómo todo proceso de inscripción pública del pasado implica siempre decisiones éticas, estéticas y, por supuesto políticas. La aproximación a un caso concreto, el Museo de la Memoria y los Derechos Humanos de Chile, permite examinar los procesos de sacralización y las dimensiones simbólico-rituales que circundan la memoria y, al tiempo, poner en evidencia cómo toda materialización institucional del recuerdo conlleva no solo a la elección de un relato sino, sobre todo, el intento de oficialización de un discurso sobre el pasado.

\section{La memoria, ¿una nueva religión civil?}

La obsesión contemporánea por la memoria, unida al miedo al olvido, han provocado que esta adquiera hoy un estatus sagrado ${ }^{7}$. En este sentido, recordar se ha convertido en el gran imperativo hasta el punto de constituir un mandato moral, así la memoria ha quedado convertida "en el vector de una religión civil con su sistema de valores, creencias, símbolos y liturgias".

Por otro lado, el particular tipo de memoria desarrollado por Occidente en la postmodernidad que es, ante todo, memoria de los sufrimientos, ha hecho que la

\footnotetext{
${ }^{7}$ Como ha señalado Kerwin Lee Lewis, tanto en los discursos académicos como en los populares, "[...] memory and its associated key words continue to invoke a range of theological concepts as well as vague connotations of spiritually and authenticity". Klein, Kerwin Lee. "On the Emergence of Memory in Historical Discourse", en Representations, núm. 69, California, University of California Press, 2000, pp. 127-147.

${ }^{8}$ Traverso, Enzo. El pasado, instrucciones de uso. Historia, memoria, política (Madrid: Marcial Pons, 2007), p. 14.
} 
víctima $^{9}$-noción íntimamente ligada a lo sagrado y a lo religioso- se convierta en un elemento central de este nuevo culto.

En la representación actual de la víctima el cuerpo ocupa un lugar central. Como bien han señalado Fassin y Bourdelais, en el espacio moral de la contemporaneidad el cuerpo -y su integridad-constituyen el eje alrededor del que pivota el discurso de lo intolerable ${ }^{10}$. Esta visión ha propiciado que el cuerpo (individual) sea considerado como sagrado e inviolable y se deposite en los Estados (y en determinados organismos sociales) la obligación de proteger dicha sacralidad.

Esa sacralización ha sido institucionalizada a través de un corpus jurídico, los Derechos Humanos (DDHH), concebidos como el marco articulador de un nuevo sistema de relaciones. Refrendar y adherirse a los mismos supone -desde el punto de vista de la comunidad internacional- un requisito ineludible para formar parte del mundo de los justos $^{11}$. Como ha señalado Negro Pavón, la falta de competencia ideológica hace que los DDHH operen más que nunca como una superideología total ${ }^{12}$. Estos se han constituido en la base sobre la que se asientan los órdenes político y jurídico de numerosos Estados -sometidos a profundos vaivenes y crisis internas- son utilizados para dotarse de una nueva legitimidad y para formar al nuevo ciudadano. Al tiempo, el intenso trabajo de diferentes organizaciones internacionales ha propiciado que sean admitidos -casi- universalmente. En un mundo interconectado la nueva creencia supera las fronteras nacionales y se articula en una lógica global. El nuevo sistema de valores sustentado, legitimado y mundializado, a tal punto que determinadas instituciones juegan un rol fundamental en la elaboración de los discursos simbólicos, discursos claramente marcados por la retórica religiosa ${ }^{13}$.

\footnotetext{
9 Noción íntimamente ligada a los derechos humanos, desde el punto de vista jurídico la definición de víctima dominante en el derecho internacional (aceptada por la mayoría de Estados y divulgada acríticamente por los Códigos penales de casi todos los países) corresponde a la Resolución 60/147 de las Naciones Unidas (aprobada en diciembre de 2005). En su Artículo 8 promulga que “[...] se entenderá por víctima a toda persona que haya sufrido daños individual o colectivamente, incluidas lesiones físicas o mentales, sufrimiento emocional, pérdidas económicas o menoscabo sustancial de sus derechos fundamentales, como consecuencia de acciones u omisiones que constituyan una violación manifiesta de las normas internacionales de los derechos humanos o una violación grave del derecho internacional humanitario".

${ }^{10}$ Fassin, Didier et Bourdelais, Patrice (Dirs.). Les constructions de l'intolérable (Paris: La Découverte, 2005), pp. 9-11.

${ }^{11}$ Los DDHH se han convertido en el parámetro sobre el que asienta una verdad ético-política utilizada por (en y desde) Occidente para valorar los avances democráticos de los Estados, especialmente de aquellos que no pertenecen al mundo occidental.

${ }^{12}$ Negro Pavón, D. "El misterio de los derechos humanos", en Intus-legere, núm. 3, Chile, Universidad Adolfo Ibáñez, 2000, pp. 9-22.

${ }^{13}$ De manera análoga a como hiciera el cristianismo en muchos periodos de su historia, los movimientos de DDHH se esfuerzan en la salvación del género humano y aplicando principios que recuerdan a la noción de alma insisten en que dichos derechos son inherentes a cada persona, como una característica ontológica fundamental. En consecuencia, de la misma manera que en la fe cristiana la salvación se vincula al destino de las almas, se establece la premisa de que el reconocimiento y el respeto de los derechos humanos es esencial para el destino de la humanidad. Elliot, Michael A. "Human Rights and the Triumph of the Individual in World", en Cultural Sociology, vol. I, núm. 3, Exeter, University of Exeter, 2007, pp. 343-363.
} 
Apenas sesenta años después de su adopción la Declaración se ha convertido en el texto sagrado de una religión secular mundial ${ }^{14}$, en el mayor artículo de fe de una cultura secular marcada por el miedo, en la lengua franca de una moral global ${ }^{15}$. Traducido a más de 300 lenguas $^{16}$, es la base sobre la que se asienta un nuevo sistema de valores morales laicos, una ética mundializada que aspira al desarrollo de una conciencia universal, basada en el descubrimiento de un interés común para el género humano y que se articula en torno a estos principios fundamentales convertidos en un dogma de $f e^{17}$. Como todo dogma exigen una adhesión sin fisuras: implican una obediencia a los mismos que debe ser percibida no solamente como necesaria sino como correcta.

Para garantizar su continuidad la creencia necesita su reproducción social, su puesta en escena a través de la repetición ritual. Ritos y ceremonias precisan a su vez de un escenario, de un lugar que dé sentido a esa verdad socialmente aceptada. En América Latina los museos de la memoria aparecen estrechamente ligados a los Derechos Humanos por lo que se han convertido en un espacio privilegiado para materializar esta creencia.

Esto es especialmente evidente en el Museo de la Memoria y los Derechos Humanos de Chile: convertido en el depositario de una misión sagrada, la reparación moral ${ }^{18}$. Aquí los Derechos Humanos son presentados como la base del nuevo sistema de valores morales que debe regir el futuro del país, un sistema que debe ser compartido por toda la sociedad chilena ${ }^{19}$. Exhibidos como la fuerza capaz de impedir, por sí

\footnotetext{
${ }^{14}$ Wiesel, Elie. "A Tribute to Human Rights", en Danieli, Y., et al. (eds.), The Universal Declaration of Human Rights: Fifty Years and Beyond (Amityville, N.Y.: Baywood, 1999), p. 3.

${ }^{15}$ Ignatieff, Michael. Human Rights as Politics and Idolatry (New Jeresey: Princeton University Press, 2001), p. 53.

${ }^{16}$ Según el Libro Guinness de los Récords se trata del documento más traducido del mundo.

${ }^{17}$ Utilizamos el término en el sentido dado por Pierre Legendre, quien lo define como el "[...] discours de la vérité légale et honorée comme telle, discours de ce qui est dit parce que cela doit être dit entendons-le au sens d'une dette rituelle, non pas au sens de devoir reconnaître le vrai dans une démarche scientifique". Legendre, Pierre. "Anthropologie dogmatique. Définition d'un concept", en Annuaire de l'École pratique des hautes études. Section des sciences religieuses, t. 105, París, 1996-1997, pp. 23-43.

${ }^{18}$ El daño moral es el infligido las creencias, los sentimientos, la dignidad, la estima social, a la salud física o psíquica; es decir, a los que la doctrina jurídica mayoritaria ha denominado derechos de la personalidad o extrapatrimoniales. La reparación del daño moral va dirigida a proporcionar en la medida de lo posible una satisfacción como compensación al sufrimiento que se ha causado. Según la declaración de fundamentos contenida en la propia página web de la institución, "El Museo de la Memoria y los Derechos Humanos es un proyecto de reparación moral a las víctimas y propone una reflexión que trascienda lo sucedido en el pasado y que sirva a las nuevas generaciones para construir un futuro mejor de respeto irrestricto a la vida y la dignidad de las personas", http:/www.museodelamemoria.cl.

${ }^{19}$ El Museo ha sido creado como “[...] un lugar donde se conservan y exhiben los testimonios y documentos que permiten mirar nuestro pasado doloroso para aprender de esa experiencia con el propósito de contribuir a que la cultura de los derechos humanos y de los valores democráticos se conviertan en el fundamento ético compartido de la sociedad chilena", http://www.museodelamemoria.cl/el-museo/ sobre-el-museo/historia-del-museo/. La negrita es de la investigación.
} 
misma, la repetición de las atrocidades del pasado ${ }^{20}$, ellos constituyen el eje del culto a la memoria desplegado en el Museo.

\section{El Museo, lugar de culto}

Desde su nacimiento hasta finales del siglo XVIII el museo fue constituido como una potente máquina de producción, administración y trasmisión de ideología. Convertido en un espacio sagrado secular, en él se custodiaban verdades trascendentales y, al tiempo, se generaba todo un sistema de creencias sobre el orden del mundo, sobre su presente y -muy especialmente- sobre su pasado. Fue precisamente ese carácter de templo, de mausoleo de la tradición, lo que condujo, a partir de los años 50 del siglo XX, a someterlo a una profunda crítica y a un cuestionamiento intelectual. La institución no salió indemne de esta querella pero lejos de desaparecer se ha reafirmado como un elemento constitutivo de la postmodernidad ${ }^{21}$.

Hoy los museos no se presentan ya como un templo del saber ni como el espacio predilecto y monopolista para el conocimiento. Sin embargo, articulados bajo una nueva lógica, muchos de ellos continúan revestidos de un aura religiosa que se traduce en un deber ético.

Por otro lado, diferentes trabajos a lo largo de las últimas décadas han insistido en la idea de que el museo, como lugar en el que se representan (y codifican) las creencias sobre el orden del mundo, su pasado y su presente, y el lugar que los individuos ocupan en él ${ }^{22}$, es un escenario privilegiado para el rito ${ }^{23}$. El poder del rito reside en su capacidad para producir contenido simbólico y vínculo social; constituye un medio para la integración del individuo en el grupo, para la construcción de una identidad tanto individual como compartida. La visita al museo puede ser vista como un medio de integración social: a través de la aprehensión de los contenidos simbólicos propuestos y por medio de la práctica de las acciones codificadas vinculadas a dichos

\footnotetext{
${ }^{20}$ El Museo tiene como misión "[...] dar a conocer las violaciones sistemáticas de los derechos humanos por parte del Estado de Chile entre los años 1973-1990, para que a través de la reflexión ética sobre la memoria, la solidaridad y la importancia de los derechos humanos, se fortalezca la voluntad nacional para que nunca más se repitan hechos que afecten la dignidad del ser humano", http:// www.museodelamemoria.cl/el-museo/sobre-el-museo/definiciones-estrategicas-2. La negrita es de la investigación.

${ }^{21}$ Las razones de su éxito y su expansión no son fáciles de explicar: para la corriente neoconservadora, la institución representa un bastión para la reminiscencia dentro de una sociedad con un profundo miedo a la pérdida de la tradición; el museo serviría así para compensar la falta de estabilidad. Para el postestructuralismo, la expansión del museo es el cáncer del fin de siglo; es el síntoma de una era glacial terminal, la expresión manifiesta del totalitarismo de la memoria muerta colectiva. Finalmente, para la Teoría Crítica, su preponderancia y su atractivo deben ser puestos en relación con la nueva fase del capitalismo y con una sociedad en la que la actividad cultural funciona, cada vez más, como una agencia de socialización. Huyssen, Andreas, Op. cit., pp. 58-73.

${ }^{22}$ Duncan, Carol. Rituales de civilización (Murcia: Editorial Nausicaa, 2007), p. 23.

${ }^{23}$ Noción cargada de sentidos, el término remite a diferentes formas de interacción y comunicación y se define tanto por su contenido y estructura como por su forma y eficacia. Está marcado por una conducta individual o colectiva, relativamente codificada, con un soporte corporal y un carácter repetitivo. Rivière, Claude. Les rites profanes (Paris: Presses universitaires de France, 1995), p. 11.
} 
contenidos, el visitante se integra en un corpus colectivo. En su dimensión ritual, el museo permite al visitante no solo el camino para una (posible) autodefinición sino sobre todo para crear (o reforzar) su ligazón con el pasado. Más allá de una simple (y normalmente obligada) actividad escolar o una voluntaria aproximación, la visita al museo supone la entrada (temporal) en un sistema social; implica el establecimiento de una relación con los otros que pasa por la creación de un vínculo $\mathrm{y}$, en ocasiones incluso, por la adscripción a determinados valores morales.

Finalmente, toda experiencia ritual tiene siempre una finalidad: purificar, renovar la identidad, conferir una nueva, restaurar el orden perdido, sanar, liberar, etc.Esto es especialmente evidente en el caso de los Museos de la Memoria y los DDHH: concebidos como lugares para la puesta en escena y la trasmisión de determinados valores morales. En ellos se busca no solo la mera contemplación y la enseñanza sino la interiorización y la asunción de dichos valores. El discurso desplegado en estas instituciones enseña a los neófitos el camino y, al tiempo, les proporciona los patrones últimos de referencia. En consecuencia, la visita a estos espacios (la práctica del ritual) posibilitaría no solo la comunión con los valores mostrados sino la profunda transformación de los visitantes en ciudadanos más justos y equitativos.

Así se pone de manifiesto el Museo de la Memoria y los Derechos Humanos de Chile, donde esa lógica transformadora parte del principio de que este espacio puede por sí mismo lograr fortalecer la voluntad nacional e impedir que nunca más se repitan hechos que afecten a la dignidad del ser humano ${ }^{24}$.

Obviamente, estos valores morales son proyectados sobre un entorno empírico -el museo- al que se dota y se carga de sentido. La memoria (traumática) se transforma entonces en un discurso museográfico y se convierte en un acontecimiento significativo y trascendente. Todo lo albergado en el interior de ese espacio queda dotado de valor y goza de una autoridad escasamente cuestionada, una autoridad reforzada por la capacidad de la institución para generar una adhesión afectiva a cada uno de los relatos allí contenidos ${ }^{25}$.

Desde el punto de vista discursivo estos relatos se articulan a través de la exposición permanente, concebida para funcionar como una unidad temática cargada de sentido. A través de ella la institución busca por tanto la coherencia y la inteligibilidad. La visita supone la entrada a espacios claramente delimitados que se recorren a través de secuencias determinadas por discursos (complejos) programados. El museo, en un acto de persuasión, busca convencer al visitante de que lo expuesto es verdadero e importante y para hacerlo

\footnotetext{
${ }^{24}$ Ambos elementos se hallan presentes en la misión del Museo de la Memoria y los Derechos Humanos de Chile, según aparece recogido en su propia página web.

${ }^{25}$ Como en todo ritual, los visitantes precisan de una disposición de receptividad que les permite ser partícipes de esa experiencia.
} 
debe crear unos argumentos y unos marcos de referencia en la propia ruta impuesta ${ }^{26}$. Por esa razón, toda experiencia museográfica puede ser analizada narrativamente.

Bucear en el proceso de transformación de la memoria traumática en discurso museográfico a partir de un ejemplo concreto, el Museo de la Memoria y los Derechos Humanos de Chile, permite ahondar en los procesos de sacralización y las dimensiones simbólico-rituales que circundan la memoria y, al tiempo, permite poner en evidencia cómo toda puesta en valor de la memoria traumática implica procesos de patrimonialización de la tragedia y del dolor $\mathrm{y}$, sobre todo, implica el control institucional del pasado. A partir del análisis del discurso del espacio que alberga al Museo, del discurso propiamente museográfico y del discurso textual, es posible examinar esta institución como un espacio productor de un mensaje definido. Como ha señalado Giner, determinados recursos culturales específicos -entre los que incluyo las instituciones museísticas- constituyen elementos poderosamente constitutivos del aura cuasi religiosa con que se tejen los mitos civiles, políticos, nacionales y hasta mundiales. Los medios de transmisión son en realidad y ante todo medios de constitución ${ }^{27}$.

\section{¿Memoria o memorias?}

En 1988 un plebiscito obligaba a Augusto Pinochet a abandonar su cargo de Presidente de la República de Chile. Había llegado al poder en septiembre de 1973 cuando un golpe de Estado derrocó al gobierno democrático de Salvador Allende e instauró una dictadura que rigió los destinos del país durante 17 años $^{28}$. El golpe truncó un (largo) proceso de democratización iniciado en los años 30 y se instaló en el imaginario colectivo como un quiebre traumático y radical ${ }^{29}$. Esa fractura continúa bien presente en la vida de los chilenos e incide - de manera determinante- en la configuración del presente.

\footnotetext{
${ }^{26}$ No podemos obviar que, habitualmente, en los museos coexisten varias narrativas y claro está, el visitante puede ignorar las propuestas o desarrollar sus propios discursos alternativos.

${ }^{27}$ Giner, Salvador. "Religión civil”, en REIS, núm. 61, Madrid, Centro de Investigaciones Sociológicas, 1993, pp. 23-55.

${ }^{28}$ Augusto Pinochet fue designado Comandante en jefe del Ejército de Chile el 23 de agosto de 1973 por el propio presidente Salvador Allende. Estuvo a la cabeza del golpe de estado que acabó con la democracia. En un primer momento, Pinochet gobernó el país como presidente de la denominada Junta Militar de Gobierno y en 1974 se autoproclamó Jefe Supremo de la Nación. En diciembre de ese mismo año se convirtió en presidente de la República, un cargo en el que sería ratificado tras un cuestionado plebiscito y la promulgación de una nueva constitución en 1980. Su mandato terminó con un nuevo plebiscito celebrado en 1988.

${ }^{29}$ Los discursos contemporáneos otorgan a ese periodo una fuerza tal que fue capaz de modificar (para siempre) los destinos del país; la violencia-dictadura aparece como un poder supremo capaz de introducir un sello permanente y de determinar la identidad de las personas y de los grupos. Piper Shafir, Isabel. Obstinaciones de la memoria: la dictadura militar chilena en las tramas del recuerdo, (tesis doctoral). Departamento de Psicología Social, Universidad Autónoma de Barcelona, 2005, pp. 179-180, http://www. archivochile.com/tesis/07_ddhh/07ddhh0001.pdf (16 de octubre del 2015).
} 
Como en el resto de las dictaduras del Cono Sur también en Chile la represión y la tortura -física y psicológica- jugaron un rol determinante en el funcionamiento y en el mantenimiento del régimen. Las violaciones de los DDHH durante este periodo fueron sistemáticas y se estima que la violencia desplegada causó más de 40.000 víctimas ${ }^{30}$.

La restauración de la democracia no supuso, sin embargo, la ruptura con la dictadura ${ }^{31}$. En opinión de diferentes autores, tras la derrota plebiscitaria de Pinochet se produjo una negociación superficial y cosmética en la que los sectores democráticos claudicaron -en numerosos frentes- bajo la lógica del mal menor. De esta manera, el paso desde el autoritarismo a la democracia se fraguó a costa de la castración y el bloqueo de la potencial capacidad transformadora del régimen democrático lo que condujo a que este quedase forzado a reproducir el orden socioeconómico creado por el pinochetismo ${ }^{32}$.

Por esa razón, la denominada transición chilena fue una democratización incompleta que dejó un régimen democrático lleno de imperfecciones y enclaves autoritarios ${ }^{33}$. Desde el punto de vista de la gobernanza, el bloqueo del sistema político institucional ha sido una característica recurrente. Dicho bloqueo se ha hecho patente, por ejemplo,

\footnotetext{
${ }^{30}$ En 1990, con la restauración de la democracia, el presidente Patricio Aylwin decreta la creación de una Comisión (Comisión Nacional de Verdad y Reconciliación) para contribuir al esclarecimiento de las violaciones de DDHH cometidas bajo el régimen militar. La Comisión fue presidida por el jurista y político Raúl Rettig por lo que es conocida comúnmente como Comisión Rettig en tanto que el informe derivado se conoce como Informe Rettig. Entre los años 2003 y 2005, bajo el gobierno de Ricardo Lagos, fue creada otra Comisión (la denominada Comisión Valech, en honor del obispo Sergio Valech que la presidió hasta su fallecimiento) para ampliar la información sobre la represión encargándose de constatar las denuncias vinculadas a la privación de libertad y torturas por razones políticas. De ella nace un segundo informe que consigna nuevas víctimas y nuevos casos de desapariciones. El Informe Rettig (publicado en 1991) contabilizó las ejecuciones y las desapariciones que cifró en 2.279 personas muertas a manos de las fuerzas de seguridad durante la dictadura. El Informe de la Comisión Valech (presentado en noviembre de 2004) cifró en más 30.000 las víctimas. Un nuevo informe presentado en agosto de 2011, elevó la cifra a más de 40.000, incluyendo detenidos desaparecidos, ejecutados políticos, víctimas de violencia política, torturados y presos políticos. Ministerio del Interior y seguridad pública-Gobierno de Chile. Informe de la Comisión Nacional de Verdad y Reconciliación, http://www.ddhh.gov.cl/ddhh_rettig.html; Informe de la Comisión Presidencial asesora para la calificación de detenidos desaparecidos, ejecutados políticos y víctimas de prisión política y tortura, http://www.ddhh.gov.cl/filesapp/informecomisionfase2.pdf.

${ }^{31}$ El plebiscito celebrado en 1988 expulsó a Pinochet de la jefatura del Estado. Sin embargo, continuó siendo comandante en jefe del ejército hasta 1998, asumiendo después el cargo de senador vitalicio que llegó a ocupar durante unos meses. En el año 2000 fue desposeído de su aforamiento parlamentario y en diciembre de ese mismo año fue procesado por secuestro y asesinato aunque el proceso fue anulado mediante un recurso de amparo. En 2001 quedó en libertad bajo fianza. Su caso fue sobreseído en 2002 tras la alegación de problemas mentales. Renunció entonces a su cargo de senador vitalicio. En 2004 la Corte de Apelaciones revocó el sobreseimiento por demencia y fue procesado por violación de los DDHH durante la Operación Cóndor. A partir de ese momento se iniciaron diversos procesos judiciales paralelos en su contra. En 2006, poco antes de su muerte, perdió de nuevo la inmunidad al ser juzgado por torturas y desaparición.

${ }^{32}$ Moulian, Tomás. "Limitaciones de la transición a la democracia en Chile", en Proposiciones, núm. 25, Santiago de Chile, Ediciones Sur, 1994, pp. 25-33, http://www.sitiosur.cl/publicacionescatalogodetalle. php?PID=3213 (23 de octubre del 2015).

${ }^{33}$ Garretón, Manuel Antonio. "La cuestión del régimen de gobierno en el Chile de hoy", en Tipos de Presidencialismo y Coaliciones Políticas en América Latina (Buenos Aires: CLACSO ed., 2001), p. 191.
} 
en el tema de las violaciones de los derechos humanos bajo la dictadura ${ }^{34}$. Por otro lado, aunque se han producido algunos acuerdos legislativos en materia de reparación a víctimas y familiares, lo cierto es que el esclarecimiento de las violaciones de DDHH es aún limitado. Los Informes Rettig y Valech implicaban el reconocimiento y la explicitación pública de los crímenes cometidos durante ese periodo pero carecían de validez jurídica ${ }^{35}$. De esta manera, aunque ambos buscaban la verdad de los hechos acaecidos, al mismo tiempo consolidaban un mecanismo que impedía la identificación y la inculpación de los responsables.

La castración democrática que ha impedido un verdadero abordaje jurídico de la violencia desplegada durante la dictadura, ha tenido su correlato paralelo en el campo de la memoria. Según Hite, las expectativas de verdad y justicia fueron frustradas por un pacto de silencio dentro de la clase política chilena, un pacto que se mantuvo hasta $1998^{36}$. Ante las diferentes miradas de ese pasado reciente que coexistían en el espacio público $^{37}$-en muchos casos opuestas entre sí-, el poder buscó oficializar un discurso de la memoria marcado por la moderación en el que la característica fundamental fue la ritualización del consenso. De esta manera, en opinión de diversos autores, la transición neutralizó las fuerzas en disputa, forzando la unanimidad de las voces, y puso en escena un espectáculo de la reconciliación que dejó a las víctimas sin referencia ni identificación compartidas ${ }^{38}$.

A pesar de que las memorias divididas (incluso antagónicas) y las luchas en torno al pasado no fueron neutralizadas y continúan bien presentes en Chile $^{39}$, lo que es indudable

\footnotetext{
${ }^{34}$ Así por ejemplo, una ley de amnistía impidió el juicio para la casi totalidad de los crímenes cometidos entre 1973 y 1978. En septiembre de 2014, durante la conmemoración del 41 aniversario del golpe de Estado, la presidenta Bachelet anunció la tramitación con suma urgencia de la derogación de dicha ley pero, a día de hoy, la ley continúa aún vigente.

${ }^{35}$ La Comisión Rettig no identifica responsables individuales de las violaciones cometidas ya que el decreto que la creó la prohíbe pronunciarse sobre responsabilidades de personas individuales. Menciona solo a organismos, fuerzas o grupos responsables. El decreto de creación de la Comisión Valech (2003) asume los mismos principios básicos. Por otro lado, el Ejecutivo estableció que los archivos generados por la Comisión serían inaccesibles durante 50 años (por lo que no serán públicos, en principio, hasta 2054).

${ }^{36}$ Hite, Katherine. "La superación de los silencios oficiales en el Chile posautoritario", en Pérotin-Dumon, Anne (Dir.), Historizar el pasado vivo en América Latina (Santiago de Chile: Universidad Alberto Hurtado, 2007), pp. 31-41.

${ }^{37}$ Steve Stern ha señalado que, a partir de 1973, los chilenos han construido cuatro memorias emblemáticas en torno a la dictadura y a la violación a los derechos humanos. Esas cuatro visiones atribuyen sentidos muy diferentes al régimen militar. La primera de estas memorias considera el 11 de septiembre como la salvación de un país en ruinas; la segunda, como una ruptura profunda que generó una situación de violencia sin precedente histórico alguno ni justificación moral; la tercera, como una situación que puso a prueba la consecuencia ética y democrática de las personas; y, la cuarta, como un episodio de la vida nacional que, dada su imposibilidad de solución y el grado de conflictividad que provoca, es mejor relegar al olvido. Stern, Steve. "De la memoria suelta a la memoria emblemática: Hacia el recordar y el olvidar como proceso histórico (Chile, 1973-1998)", en Mario Garcés, et al. (comps.), Memoria para un nuevo siglo: Chile, miradas a la segunda mitad del siglo XX (Santiago: LOM Ediciones, 2000), pp.11-33.

${ }^{38}$ Richard, Nelly. "La crítica de la memoria", en Cuadernos de Literatura, vol. XV, núm. 8, Bogotá, Pontificia Universidad Javierana, 2002, pp. 187-193.

${ }^{39}$ Así se puso de manifiesto, por ejemplo, durante el arresto de Pinochet en Londres en 1999 y a fines del año 2006 a raíz de su muerte. Sobre las luchas de la memoria en Chile: Waldman, Gilda. "Chile: la persistencia de las memorias antagónicas”, en Política y Cultura, núm. 31, México, UAM, 2009, pp. 211-234.
} 
es que con la transición comenzó un proceso de memorialización (tanto discursivo como material) destinado a consolidar una memoria hegemónica ${ }^{40}$, una memoria sin desarmonía ni fisuras, una memoria emblemática, símbolo de un nuevo espíritu nacional marcado por el consenso y el respeto a los derechos humanos, una memoria que termine por constituirse en el relato definitivo de una comunidad imaginada.

En ese proceso se inscribe el Museo de la Memoria y los DDHH. La institución representa la culminación de un largo proceso por dar respuesta a las demandas de las víctimas y de las organizaciones de DDHH. Su nacimiento se vincula a las recomendaciones emanadas del Informe Rettig, a las políticas de apoyo, a la construcción de memoriales del presidente Ricardo $\operatorname{Lagos}^{41} \mathrm{y}$, muy especialmente, a la decisión de la presidenta Michelle Bachelet ${ }^{42}$. Pero sobre todo, como ha señalado Lazzara, el Museo representa el punto culminante de una política reconciliatoria y oficialista y constituye el emblema de una época en la que la unidad aparece como el deseo (la utopía y la fantasía) de una comunidad políticamente imaginada ${ }^{43}$.

\section{El espectáculo ${ }^{44}$ del pasado}

La memoria traumática es, sin duda, un patrimonio controvertido. Esto es especialmente evidente en Chile donde, aún hoy, numerosas cuestiones vinculadas a la última dictadura militar continúan siendo tabúes en el debate público. Aunque casi nadie niega ya (al menos públicamente) las violaciones de los derechos humanos cometidas durante el régimen de Pinochet, las discrepancias sobre la interpretación de ese pasado reciente son muy profundas. En consecuencia, la inscripción pública del mismo y el intento de construcción de un relato unificado plantean arduas controversias.

Como bien ha señalado Jelin, todo espacio de rememoración es un espacio de lucha por la legitimación y la imposición de un discurso oficial conmemorativo. El nacimiento del Museo de la Memoria y los Derechos Humanos de Chile es un buen ejemplo de cómo el pasado, especialmente si es reciente y traumático, es siempre objeto de disputa. Desde el momento mismo del anuncio de su creación por parte de la presidenta Bachelet en 2007 empezaron a oírse voces críticas en contra del proyecto. Además de la oposición procedente de los sectores pro-pinochetistas (aún con gran fuerza en el país en esas fechas), al Museo se opusieron también numerosos historiadores quienes exigían una contextualización de los hechos que permitiese comprender el quiebre

\footnotetext{
${ }^{40}$ Obviamente, la fuerza y el reconocimiento de esas memorias hegemónicas no son inmutables, pudiendo consolidarse pero también debilitarse, obligando a la permanente reconstrucción.

${ }^{41}$ Ricardo, Lago. Prólogo: reflexiones y propuestas de S.E. el presidente de la república, Ricardo Lagos Escobar, http://www1.umn.edu/humanrts/links/PrologoPresidente.pdf.

${ }^{42}$ El Museo constituye, en cierto sentido, uno de los proyectos estrella de su presidencia, una presidencia marcada por un profundo carácter simbólico dada su propia trayectoria biográfica.

${ }^{43}$ Lazzara, M. J. "Dos propuestas de conmemoración pública: Londres 38 y el Museo de la Memoria y los Derechos Humanos (Santiago de Chile)", en A Contracorriente, vol. VIII, núm. 3, Raleigh, North Carolina State University, Spring, 2011, pp. 55-90.

${ }^{44}$ Utilizamos el término espectáculo en la tercera acepción proporcionada por la RAE: "Cosa que se ofrece a la vista o a la contemplación intelectual y es capaz de atraer la atención y mover el ánimo infundiéndole deleite, asombro, dolor u otros afectos más o menos vivos o nobles".
} 
democrático ${ }^{45}$. Por otro lado, aunque en la concepción inicial del proyecto se otorgaba un espacio importante a los organismos de DDHH, el gobierno de Bachelet modificó ese presupuesto y esas voces fueron relegadas ${ }^{46}$. Y así, finalmente, tras esquivar las luchas que se tejen alrededor de la memoria, el Museo se convirtió en una iniciativa controlada destinada a centrar la memoria nacional.

Desde su primera piedra la institución se vinculó, como no podía ser de otra manera, al Holocausto, tropo universal del trauma histórico ${ }^{47}$. El Museo fue inaugurado en 2010 y el acto tuvo también su momento de contra-memoria ${ }^{48}$.

La fecha escogida para la apertura constituía un momento profundamente simbólico para la nación: en una peculiar maniobra el rito de consagración del nuevo espacio enlazaba con el rito de conmemoración destinado a recordar el inicio de un tiempo nuevo, la Independencia. El momento quedaba así revestido de un aura inaugural de época e identidad nacional.

Ese aura inaugural, esa voluntad de dar forma a un tiempo nuevo, se puso también en evidencia desde el punto de vista arquitectónico: en lugar de recuperar -como sede del Museo- alguno de los espacios tocados por la huella de la violencia ${ }^{49}$, se decidió levantar un edificio que acogiera a toda la ciudadanía ${ }^{50}$. El lugar escogido fue un terreno de dos hectáreas de propiedad fiscal ubicado en la Avenida Matucana, una de las calles de mayor jerarquía de la ciudad y con un marcado carácter cultural. El lugar se encuentra frente a la denominada Quinta Normal, el espacio que en 1875

\footnotetext{
${ }^{45}$ Las principales críticas de los opositores se articulaban en torno a cuatro puntos: la propia pertinencia del proyecto; la ausencia de contextualización histórica; el período abarcado, y la definición del estatus de víctima. Aunque se trata de un debate político y, especialmente, académico, su impacto en la opinión pública ha sido muy significativo.

${ }^{46}$ Hite, Katherine y Cath, Collins. "Memorial Fragments, Monumental Silences, and Reawakenings in 21stcentury Chile”, en Millennium: Journal of International Studies, vol. XXXVIII, núm. 2, London, London School of Economics, 2009, pp. 379-400.

${ }^{47}$ Durante la colocación de la primera piedra del Museo de la Memoria y los Derechos Humanos (el 10 de diciembre de 2008) la presidenta Michelle Bachelet aludió explícitamente al genocidio de los judíos durante la Segunda Guerra Mundial. Sobre la fuerza del imaginario del Holocausto en América Latina: Montealegre Iturra, Jorge. "El imaginario del Holocausto en la memoria social de las dictaduras latinoamericanas", en Cultura, lenguaje y representación, vol. X, Castellón de la Plana, Universidad Jaume I, 2012, pp. 97-110.

${ }^{48}$ Durante el acto, al que asistieron más de tres mil personas (entre los que destacan las víctimas y los representantes de organizaciones de derechos humanos), una mujer mapuche escaló una de las torres de iluminación del patio central, pidiendo justicia por los derechos de su pueblo, reclamando libertad a los presos políticos y denunciando que "[...] en Chile se violan los derechos humanos". La denuncia estaba ligada a la muerte del estudiante Matías Valentín Catrileo Quezada a manos de los carabineros el 3 de enero de 2008. Morales, Karina. "Incidentes empañan inauguración del Museo de la Memoria”, en Emol, Santiago de Chile, http:/www.emol.com/noticias/nacional/2010/01/11/393405/incidentes-empananinauguracion-del-museo-de-la-memoria.html (11 de enero del 2010).

${ }^{49}$ En 2007 existían en la región metropolitana de Santiago de Chile cerca de 250 lugares de memoria de muy variadas características. Entre ellos destacan, sin duda, Londres 38 y Villa Grimaldi, ambos centros de detención y tortura.

${ }^{50}$ Palabras de Verónica Serrano Madrid, directora nacional de arquitectura del Ministerio de Obras Públicas de Chile en el momento de la creación del Museo. Serrano Madrid, Verónica. "Proyecto arquitectónico", en Museo de la Memoria y los Derechos Humanos (Santiago de Chile: Museo de la Memoria), p. 18.
} 
acogió la celebración de la Exposición Internacional de Santiago en la que los países civilizados mostraron sus adelantos técnicos y científicos. Un año después, en 1876, el palacio construido para ese evento se convirtió en la sede del Museo Nacional de Historia Natural. Y así, en una pirueta del destino (o quizá no), el Museo encargado de contener (y trasmitir) los sagrados valores de la postmodernidad -los DDHH- se ubica al lado de aquel espacio que en el siglo XIX afirmaba contener los sagrados valores de la civilización.

Con el fin de construir "un lugar que dignifique a las víctimas" 51 se convocó un concurso internacional ${ }^{52}$ en el que ganó el estudio brasileño liderado por el arquitecto Mario Figueroa. En opinión del Jurado el proyecto había conseguido “[...] destacar simbólicamente el tema de los $\mathrm{DDHH}$, haciéndolo transparente, luminoso, proponiendo temas de tecnología y modernidad que lo facultaban como un edificio del Bicentenario"53. La frase, profundamente simbólica, condensa toda una declaración de principios: transparente como el nuevo poder (político) que se muestra proclive a esclarecer la verdad; luminoso como un tiempo nuevo; tecnológico y moderno como los paradigmas del futuro y, finalmente, profundamente identitario.

El acceso al Museo se efectúa a través de una rampa que desciende desde una de las calles laterales del predio (calle Catedral). En los muros que delimitan el acceso a la institución aparecen los 30 artículos de la Declaración Universal de los DDHH, nuevas tablas de la Ley que representan el código ético que ha de regir la conducta del nuevo ciudadano. Por esa razón, el dogma de fe queda fijado en la piedra y lo hace además con letras de cobre ${ }^{54}$. El Museo explicita así su adhesión a esta creencia, a esta nueva ética mundializada. Al presentarlos como elemento introductorio de la exposición permanente, la institución está mostrando a los neófitos el camino, proporcionándoles los patrones últimos de referencia.

Según los propios arquitectos, el museo debía constituir " [...] la memoria evidenciada, emergente, flotante, suavemente elevada. Un arca donde se pueden depositar todas las reminiscencias de la historia chilena" ${ }^{55}$. De esta manera, en la plaza que recibe al visitante $^{56}$ se alza el edificio principal, denominado Barra, un cuerpo de 80 metros

\footnotetext{
${ }^{51}$ Ibid.

${ }^{52}$ La convocatoria tuvo una gran acogida: se registraron 407 inscripciones y finalmente hubo 56 participantes. 53 "Selección final de las propuestas arquitectónicas", en Museo de la Memoria y los Derechos Humanos (Santiago de Chile: Museo de la Memoria), p. 32.

${ }^{54}$ Chile es el mayor productor y exportador de cobre en el mundo y este material juega, sin duda, un papel esencial en el imaginario colectivo de país.

${ }^{55}$ Figueroa, Mario; Fehr, Lucas y Díaz, Carlos. "El concepto", en Museo de la Memoria y los Derechos Humanos (Santiago de Chile: Museo de la Memoria), p. 36.

${ }^{56}$ Concebida como un espacio de encuentro (se trata de una explanada de 6.000 metros cuadrados) resulta sintomático que se encuentre -literalmente- sepultada y encerrada. La plaza se sitúa a seis metros por debajo del nivel de las calles colindantes. La razón estructural es que el terreno había sido objeto de una excavación por el Metro de Santiago quien lo había adquirido para construir una estación. Los arquitectos no modificaron ese desnivel por lo que, desde la perspectiva visual del peatón, la plaza aparece comprimida y hundida. Por otro lado, una vez inaugurado el Museo, la explanada pública se cerró con rejas para limitar su uso.
} 
de largo por 18 metros de ancho que cruza el terreno de oriente a poniente y que, según sus creadores, evidencia lo sublime de la memoria ${ }^{57}$. Está concebido como un gran volumen "[...] suspendido sobre la Plaza, edificado como un cubo de cristal que pareciera estar levitando sobre dos fuentes de agua" 58 . Las fachadas norte y sur están realizadas en cristal templado y laminado lo que otorga al edificio una particular luminosidad. Para amortiguar los efectos de la luz, una piel en láminas de cobre las recubre $^{59}$. De esta manera, un elemento profundamente simbólico para la identidad nacional chilena -el cobre- envuelve a la memoria para protegerla eternamente ${ }^{60}$.

Internamente, el edificio se organiza en tres pisos. Desde el momento mismo de la entrada, queda explicitado el marco de referencia que encuadra y sostiene el discurso contenido en el Museo. Así, en la sala 1, bajo el lema "Derechos Humanos, desafío universal", el visitante se confronta a un muro de información que recoge los trabajos de 32 Comisiones de Verdad en diferentes partes del mundo. En una suerte de comunión colectiva, el dispositivo museográfico pretende así poner en evidencia el valor global del discurso de los DDHH, ese nuevo texto sagrado de una religión secular mundial. Al mismo tiempo, el Museo se presenta como la institución que ha sido capaz de abordar el desafío que supone el tratamiento de dicha cuestión. A partir de este momento el proceso de legitimación se ha puesto en marcha.

En un costado de la misma sala, bien custodiados en una vitrina, se muestran los Informes Rettig y Valech, que recogen los resultados de las Comisiones de Verdad en Chile ${ }^{61}$. Ambos informes constituyen un elemento sustancial en el proceso de construcción del relato. Carentes de todo valor jurídico han sido convertidos, a través del dispositivo museográfico, en objeto de museo destinado a sustentar y legitimar el discurso contenido en su interior. Además, constituyen una prueba de su validez y su credibilidad. Al tiempo, ambos documentos delimitan (y sacralizan) lo que forma parte de la memoria de la dictadura ya que la base constitutiva del discurso narrativo es la verdad avalada por el Estado.

El tercer recurso visual que completa el discurso de la sala está constituido por una instalación denominada Memoriales. Se trata de una serie de fotografías de diferentes lugares de memoria existentes en Chile. Las imágenes aparecen clavadas sobre una estructura de piedra con la forma del territorio nacional. Al evocar a la comunidad bajo esa clave, se estableció también un vínculo entre nación, memoria

\footnotetext{
${ }^{57}$ Figueroa, Mario, et al., Op. cit., p. 38.

${ }^{58}$ Ibid.

${ }^{59}$ La piel fue concebida para filtrar la luminosidad y evitar los efectos dañinos de la luz sobre los fondos expuestos. Está colocada a un metro de distancia de los cristales lo que, desde el punto de vista práctico, permite la limpieza permanente de las fachadas.

${ }^{60}$ Según el dicho popular "El cobre es eterno".

${ }^{61}$ Como ya ha sido señalado (nota 33), ambos informes recogen las víctimas de la dictadura, incluyendo detenidos desaparecidos, ejecutados políticos, víctimas de violencia política, torturados y presos políticos.
} 
y territorio, un vínculo que no es baladí en un país donde la cuestión de los límites territoriales está muy presente ${ }^{62}$.

El espacio de acogida sirve así como marco introductorio que fija los límites del discurso que va a desplegarse a lo largo del recorrido. Sin embargo, la mirada universal se abandona pronto para pasar a una mirada estrictamente local alrededor de la cual pivota el núcleo duro de la exposición permanente. Así, en el primer piso, la narración se estructura en torno a seis salas ${ }^{63}$ que buscan contar la historia del país desde el momento cero, ese 11 de septiembre de 1973, cuando se produjo el quiebre de la democracia. A lo largo de las mismas se abordan los trágicos acontecimientos de ese día (Zona 1) así como los primeros momentos del régimen -con la proclamación del estado de emergencia, la militarización del país, el cierre del Congreso, etc.- (Zona 2), y la condena internacional al golpe y los ecos del mismo fuera de las fronteras del país (Zona 3). Los recursos audiovisuales (la modernidad y la tecnología) constituyen elementos esenciales en la construcción y en la validación del discurso desplegado en estas zonas. Soportes como los registros visuales y sonoros son utilizados como pruebas destinadas a otorgar credibilidad y legitimidad a la narración. Ambas quedan además reforzadas por los personajes escogidos para narrar el discurso: protagonistas directos de los hechos pero sobre todo, personajes relevantes de ese pasado, testigos autorizados que no hacen sino contribuir a consolidar la validez del relato ${ }^{64}$.

Uno de los elementos más significativos en estas zonas es la ausencia de contextualización. La narración conduce a un pasado congelado, inmovilizado, sin dimensión histórica. Los hechos se exponen como si la mera exhibición pudiera explicar lo sucedido. Por otro lado, al alejarse del carácter constitutivo de la memoria (su subjetividad), la museografía desplegada es profundamente archivística y se apoya de manera fundamental en los vestigios verdaderos: procesos judiciales, grabaciones e imágenes ${ }^{65}$. El Museo pone así en evidencia las tensiones entre la memoria y la historia

\footnotetext{
${ }^{62}$ Se puede pensar, por ejemplo, en el conflicto abierto con Bolivia agudizado en 2013 (durante el mandato de Piñera en Chile) cuando Evo Morales demandó a Chile ante la Corte Internacional de Justicia. Una buena muestra de la tensión entre ambos países se produjo el pasado mes de septiembre (2015) y tuvo precisamente como escenario el Museo de la Memoria y los DDHH. Cádiz, Pablo. "Bolivia acusa 'veto' por negativa a facilitar Museo de la Memoria para acto con García Linera", en Tele13, http://www.t13.cl/ noticia/politica/bolivia-acusa-veto-negativa-facilitar-museo-memoria-acto-garcia-linera (3 de septiembre del 2015).

${ }^{63} 11$ de septiembre; Fin del Estado de Derecho; Una nueva institucionalidad, Condena Internacional. La dictadura traspasa las fronteras; Represión y tortura; Artesanía carcelaria, y El dolor de los niños.

${ }^{64}$ Destaca, sin duda, el registro sonoro del último discurso de Salvador Allende.

${ }^{65}$ Todo museo funciona en realidad como un dispositivo archivístico ya que despliega un sistema de organización del saber a través de la clasificación. Por otro lado, los museos poseen sus propios archivos que constituyen un mecanismo esencial en la producción y administración del conocimiento y en la legitimación del mismo. En el caso del Museo de la Memoria y los DDHH, el Archivo juega un papel determinante: busca -según se explicita en la propia página web de la institución- "[...] resguardar la información contenida, y preservar la historia de la defensa de los derechos humanos en Chile durante los años de Dictadura. Constituyen una fuente esencial de consulta permanente para el establecimiento de la verdad, la administración de justicia y la dignificación de las víctimas, constituyéndose en un relato imprescindible para la investigación y educación en derechos humanos". La negrita es de la investigación.
} 
y aunque teóricamente, opta por posicionarse al lado de la primera ${ }^{66}$, en un proceso de búsqueda de legitimación, la institución se aferra a la objetividad de la prueba. El resultado es, por un lado, una sobredosis informativa que satura al visitante, y por otro, una cosificación de la memoria.

La segunda parte de este espacio está conformado por tres salas denominadas Represión y tortura (Zona 4), El dolor de los niños (Zona 5) y Artesanía carcelaria (Zona 6). Aquí, la temática desplaza a la cronología y la museografía se aleja de la objetivación para penetrar, de manera directa, en el campo de la emoción. La luz se atenúa e incluso aparece la oscuridad, símbolo del horror. Aquí las víctimas se convierten en las protagonistas del relato. Diferentes objetos elaborados por los presos durante su confinamiento nos aproximan al universo de lo íntimo. Los relatos, las cartas y los dibujos de los niños pretenden hacer una conexión con el dolor de las víctimas más inocentes. Pero sin duda, el espacio más simbólico lo constituye la sala denominada Represión y tortura: aislado del resto de los sectores y cubierto de una tela negra, este espacio introduce al visitante en las atrocidades de la dictadura. Las paredes de la sala están forradas con la lista de las víctimas del Informe Valech. Dentro se encuentra un listado detallado de los diferentes centros de detención y tortura del país y una lista de las personas que no sobrevivieron. Y allí están ubicadas también, en el centro del espacio, una parrilla (una cama metálica) y una máquina para aplicar descargas eléctricas; ambas buscan aproximarnos a la experiencia del horror ${ }^{67}$. En este espacio se explicitan de manera prolija los métodos de tortura y se escuchan los testimonios de diferentes víctimas que verbalizan los suplicios y vejaciones sufridas. El Museo apuesta aquí por una museografía de la literalidad traumática donde la experiencia sensorial y la emoción juegan un papel esencial. El testimonio de las víctimas pivota alrededor del cuerpo y las violencias ejercidas sobre él. Aquí, el visitante se confronta a la profanación sufrida por esa entidad sagrada e inviolable. El discurso de lo intolerable alcanza aquí su grado máximo. El testimonio de las víctimas se integra en el discurso global con el fin de dotarlo de mayor veracidad. Pero sobre todo, ese testimonio pretende constituir un exempli: los narradores han sobrevivido, han podido salir del horror. Si ellos pudieron, entonces también la nación podrá dejar atrás su pasado doloroso. Esa salida del horror, individual y colectiva, está magistralmente tratada desde el punto de vista museográfico: al abandonar la pequeña sala oscura en la que se narran las atrocidades, unos pocos metros bastan para devolver al espacio luminoso ${ }^{68}$.

El segundo piso se articula en torno a tres salas diferentes: Demanda de Verdad y Justicia, Lucha por la Libertad y Retorno a la Esperanza. La museografía busca poner

\footnotetext{
${ }^{66}$ En las diferentes reuniones personales mantenidas con el equipo del Museo durante el mes de junio de 2015, los entrevistados insistieron de manera reiterada en que no se trata de un museo de historia.

${ }^{67}$ Ambos artefactos eran propiedad de la Fundación Salvador Allende y fueron donados a la colección permanente del Museo.

${ }^{68}$ La luminosidad es un elemento central en el Museo. Desde tiempos remotos, la luz posee profundos significados simbólicos. Ella marca el nacimiento de la creación ("Dijo Dios: haya luz, y hubo luz". Gen. 1:3), supone la separación de las tinieblas. Estas son oscuridad, miedo, desesperación, caos, horror. La tiniebla es el infierno. Por el contrario, la luz aparece asociada al Bien, la Verdad y el Conocimiento.
} 
en evidencia las acciones realizadas por los diferentes organismos de DDHH desde los inicios de la dictadura. También aquí el recurso a la memoria documental es constante. Las salas Demanda de Verdad y Justicia y Lucha por la Libertad se articulan en torno a una narrativa que presenta un desfile de todos los actores que participaron en la lucha contra la dictadura para conducir al país hacia la senda de la democracia ${ }^{69}$. La narrativa desplegada en el discurso museográfico, lineal y secuencial, pretende hacer comprender el proceso que condujo al fin de la dictadura. El Museo intenta trasmitir la idea de que tras la caída del régimen se halla la lucha de (toda) la sociedad por los DDHH. Y así, ese relato sin fisuras nos conduce de manera natural a la última sala de este espacio, Retorno a la Esperanza donde se presenta el plebiscito de 1988 y la consecuente salida del poder de Pinochet. En esa retórica triunfalista, en ese discurso cerrado en el que no hay espacio para las fisuras, no se problematiza, por ejemplo, que en ese referéndum que condujo al país hacia la democracia, el SI a Pinochet obtuvo más del $40 \%$ de los votos. En una simplificación de los hechos se oculta la profunda división que marcó el final de ese periodo y que, aún hoy, caracteriza en gran medida a la sociedad chilena.

En este segundo piso existe un lugar que rompe con el modelo secuencial narrativo desplegado en el espacio: la sala Ausencia y Memoria, un memorial concebido para honrar y recordar a los muertos. Rodeado de velas (artificiales) y frente a cientos de fotos (recuerdo-fetiche) de los desaparecidos, el visitante se sitúa frente a las víctimas sacrificadas. Como un altar, este lugar constituye el punto más sagrado del templo. También aquí se hace presente el vínculo entre tecnología y verdad y así, una pantalla permite conocer los nombres de las víctimas. Sin embargo, la información que la modernidad proporciona no revela ningún rasgo biográfico relacionado con su militancia o su condición étnica. No hay por tanto inscripción en la historia por lo que se las confina, aún más, a su condición de víctimas.

La narración culmina con un video filmado en el simbólico Estadio Nacional en marzo de 1990. Allí, el presidente Patricio Aylwin recibe la franja presidencial y pronuncia un emotivo discurso en el que proclama la celebración de un nuevo amanecer. Al recordar los valores legados por los padres de la Patria, esos que configuran el alma de Chile, la nación se "[...] compromete a no extremar los conflictos, sino a procurar resolverlos mediante soluciones consensuales para que nunca más se repitan esos hechos" $"$. El horror ha terminado.

La visita aproxima a ese horror pero estamos a salvo: este está confinado a un tiempo ya pasado, un tiempo que no se repetirá porque hemos aprendido los nuevos valores que garantizan que esos hechos nunca más volverán a reproducirse. Basta con rememorar el mandato moral. El Museo, esa escuela del nuevo ciudadano, es el

\footnotetext{
${ }^{69}$ Entre ellos, se otorga especial relevancia al papel jugado por la Iglesia Católica y, en particular por el cardenal Raúl Silva Enríquez. El cardenal constituye uno de los pocos actores relacionados con la historia de la dictadura que es alabado casi universalmente por los chilenos.

${ }^{70}$ Aylwin, Patricio. "Discurso de S.E. el Presidente de la República”, en Ortega R., Eugenio y Moreno B., Carolina (comps.), ¿La concertación desconcertada? (Santiago de Chile: LOM Eds., 2002), http://www. memoriachilena.cl/archivos2/pdfs/MC0055348.pdf.
} 
garante de que eso no ocurra. La práctica del ritual transforma. Conjurado el peligro, ante nosotros se abre un luminoso futuro. Como no podía ser de otra manera en una sociedad de consumo, esta historia tiene un happy end.

La institución no olvida, sin embargo, provee al visitante de su dosis de realidad y ofrece la posibilidad de vivir una experiencia particular, la experiencia de la dictadura. En una sociedad que busca ávidamente la verdad de los hechos, incluyendo la aproximación (pasajera) a la tortura y al sufrimiento (del otro), el Museo garantiza el testimonio en primera persona, el acceso a la autenticidad. Los dispositivos museográficos desplegados instauran la emoción como forma de aproximación a las víctimas y esta, erigida en un fin en sí misma, se impone a cualquier otra forma de conocimiento. La museografía se aferra a la literalidad traumática y el Museo transmite el mensaje de que la memoria no necesita de ninguna explicación. Al mismo tiempo, la institución busca hacer de esa memoria trágica algo transitable: la imponente edificación, tanto en su aspecto exterior como interior, la estetización de los dispositivos, la fascinación que provocan determinadas composiciones -como el altar de las víctimas-, la omnipresencia de la luz (metáfora del Bien, la Verdad y el Conocimiento), ayudan a atenuar el tono trágico. A lo largo de toda la exposición, conceptos y problemas son reemplazados por formas e imágenes, haciendo digerible el pasado traumático. De esta manera, la memoria, una vez institucionalizada y ordenada, es transformada en espectáculo, en un "objeto de consumo, estetizado, neutralizado y rentable"71.

Finalmente, como producto que participa de la lógica de la economía de mercado, el Museo proporciona otro camino para adquirir la memoria. Así, en su tienda (de recuerdos) descubrimos cómo las reivindicaciones de ese tiempo ya acabado son hoy reclamos publicitarios, imagen-mercancía, íconos pop que estampan camisetas. Desideologizado, el pasado parece haber quedado reducido a unos cuantos objetos de consumo.

\section{Reflexiones finales}

La obsesión contemporánea por la memoria, unida al terror y al olvido, han provocado que esta adquiera un estatus sagrado. Recordar se ha convertido en un mandato moral. Esto es especialmente evidente en las sociedades latinoamericanas con pasados recientes marcados por la violencia. Aquí, la memoria traumática ha quedado convertida en una religión civil que cuenta con su propio dogma, los Derechos Humanos, instituidos como el principal artículo de fe de una sociedad marcada por el miedo a la (imposible) repetición del pasado.

Esta extraordinaria importancia otorgada a la memoria traumática ha hecho que su inscripción pública se convierta en una cuestión central del presente latinoamericano.

\footnotetext{
${ }_{71}$ Traverso, Enzo. "Historia y memoria. Notas sobre un debate", en Franco, Marina y Levín, Florencia (comps.), Historia reciente. Perspectivas y desafios para un campo en construcción (Buenos Aires: Editorial Paidos, 2007), p. 68. Aparece entonces el turismo de la memoria que implica no solo la creación de museos sino toda una estructura administrativa y logística complementaria e incluso estrategias publicitarias específicas para dar a conocer esos lugares.
} 
Así lo evidencia la proliferación de espacios conmemorativos entre los que destacan, sin duda, los Museos de la Memoria y los Derechos Humanos: concebidos como lugares para la celebración del culto al pasado (traumático) y para la trasmisión de una nueva ética globalizada, estas instituciones instan a los visitantes a adherirse a una comunidad organizada en base a un nuevo sistema de valores morales.

Esto es especialmente evidente en el Museo de la Memoria y los Derechos Humanos de Chile: convertido en el depositario de una misión sagrada, la reparación moral, la institución que se presenta además como el lugar capaz de lograr la transformación del presente e impedir la repetición del pasado. Una misión civilizadora que implica el intento de consolidación de una memoria hegemónica y controlada.

El Museo ofrece una imagen del país marcada por el triunfo del consenso. Este consenso, mucho más imaginado que real, se sacraliza como un momento inaugural. La reconciliación y la unidad como elementos triunfantes y definidores del nuevo ser nacional. El Museo constituye el espacio escogido para preservar y trasmitir los valores morales que deben encarnar el nuevo espíritu de la patria y de la colectividad. La proclamación comunitaria de la nueva creencia común, los Derechos Humanos, bastará para proteger a la nación de todos los peligros que puedan acecharla. Al enarbolar esta bandera, el Museo invita a recordar como forma de evitar la repetición de las atrocidades. Desafortunadamente, sabemos bien que el recuerdo, por sí mismo, es incapaz de neutralizar los males del presente y del futuro.

Sin duda, el Museo posee el mérito de haber transformado la memoria en una referencia visual colectiva. Sin embargo, la construcción de esta referencia se ha realizado a partir de la evocación ritual del pasado, un pasado que ha perdido toda su dimensión histórica.

La auto-impuesta prohibición de tocar la memoria de las víctimas desplegada a lo largo del recorrido inhibe de la comprensión del hecho histórico y, sobre todo, impide la reflexión (crítica) sobre sus causas y sus consecuencias. Al tiempo, esa auto-prohibición sacraliza el pasado y lo condena a permanecer inmóvil. Este queda relegado a un tiempo comprimido, el de la dictadura, ya terminado. Y las víctimas quedan confinadas en ese pasado. Los hechos ocurridos (dramáticos y traumáticos) no se insertan en un contexto global que permita una lectura y una apropiación más allá de lo local. De esta manera, el Museo contribuye a generar un nuevo tipo de identidad (nacional) marcada por la excepcionalidad traumática.

Sin ninguna duda, las víctimas reciben aquí un homenaje pero quedan confinadas a un tiempo de barbarie, un tiempo que -según se desprende del discurso desplegado en la exposición permanente- está liquidado y no puede volver. Al restringir los males de la nación al pasado dictatorial, el Museo genera la (falsa) ilusión de que esos males están superados y no pueden regresar. Y al hacerlo, se diluye la necesidad de estar alerta y vigilante frente a nuevos peligros. 
El relato desplegado a lo largo de la exposición permanente, sin fisuras ni contradicciones, sacraliza la memoria traumática hasta convertirla en intocable. El Museo queda transformado en el lugar para la celebración de su culto y para la proclamación comunitaria de la nueva creencia común, los Derechos Humanos; un lugar cargado de prácticas ritualizadas que expulsan de la institución todo lo que desafía al orden consagrado, todo lo que promueve el escepticismo.

Fuera del perímetro acotado, en los costados de la memoria domesticada, en la calle, las heridas del pasado se abren y supuran. Son la prueba evidente de los múltiples conflictos político-sociales no resueltos.

\section{Bibliografía}

\section{Fuentes primarias}

\section{Libros}

Museo de la Memoria y los Derechos Humanos. Santiago de Chile: Museo de la Memoria.

\section{Publicaciones en Internet}

Informe Rettig. Informe de la Comisión Nacional de Verdad y Reconciliación, http:// www.ddhh.gov.cl/ddhh_rettig.html.

Informe de la Comisión Presidencial Asesora para la Calificación de Detenidos Desaparecidos, Ejecutados Políticos y Víctimas de Prisión Política y Tortura, http:// www.ddhh.gov.cl/filesapp/informecomisionfase2.pdf.

\section{Fuentes Secundarias}

\section{Libros}

Barel, Yves. La société du vide. Paris: Éditions du Seuil, 1984.

Duncan, Carol. Rituales de civilización. Murcia: Editorial Nausicaa, 2007.

Fassin, Didier y Bourdelais, Patrice (Dirs.). Les constructions de l'intolérable. Paris: La Découverte, 2005.

Hartog, François. Régimes de historicité. Présentisme et expériences du temps. Paris : Éditions du Seuil, 2012.

Huyssen, Andreas. En busca del futuro perdido. Cultura y memoria en tiempos de globalización. Buenos Aires: Fondo de Cultura Económica, 2001. 
Sacralización, ritualización y espectáculo en torno al pasado: El Museo de la Memoria...

Ignatieff, Michael. Human Rights as Politics and Idolatry. New Jeresey: Princeton University Press, 2001.

Klein, Kerwin Lee. From History to Theory. Berkeley and Los Angeles: University of California Press, 2011.

Rivière, Claude. Les rites profanes. Paris: Presses universitaires de France, 1995.

Rousso, Henry. Le syndrome de Vichy. Paris: Le Seuil, 1987.

Traverso, Enzo. El pasado, instrucciones de uso. Historia, memoria, política. Madrid: Marcial Pons, 2007.

\section{Capítulos de libros}

Garretón, Manuel Antonio. "La cuestión del régimen de gobierno en el Chile de hoy", en Tipos de Presidencialismo y Coaliciones Políticas en América Latina. Buenos Aires: CLACSO, ed., 2001.

Hite, Katherine. "La superación de los silencios oficiales en el Chile posautoritario", en Pérotin-Dumon, Anne (Dir.), Historizar el pasado vivo en América Latina. Santiago de Chile: Universidad Alberto Hurtado, 2007.

Legendre, Pierre. "Anthropologie dogmatique. Définition d'un concept", en Annuaire de l'École pratique des hautes études. Section des sciences religieuses, t. 105, Paris, 1996-1997.

Pécaut, Daniel. "Memoria imposible, historia imposible, olvido imposible”, en Belay, Raynald; Bracamont, Jorge: Degregori, Carlos Iván y Vacher, Jean Joinville (Dirs.); Memorias en conflicto, Aspectos de la violencia política contemporánea. Lima: IEPIFEA, 2004.

Stern, Steve. "De la memoria suelta a la memoria emblemática: Hacia el recordar y el olvidar como proceso histórico (Chile, 1973-1998)", en Garcés, Mario, et al. (comps.), Memoria para un nuevo siglo: Chile, miradas a la segunda mitad del siglo $X X$. Santiago: LOM Ediciones, 2000.

Traverso, Enzo. "Historia y memoria. Notas sobre un debate", en Franco, Marina y Levín, Florencia (comps.). Historia reciente. Perspectivas y desafios para un campo en construcción. Buenos Aires: Editorial Paidos, 2007.

Wiesel, Elie. "A Tribute to Human Rights", en Danieli, Y., et al. (eds.), The Universal Declaration of Human Rights: Fifty Years and Beyond. Amityville, N.Y.: Baywood, 1999.

\section{Artículos en revistas}

Confino, Alon. "Collective Memory and Cultural History: Problems of Method", en The American Historical Review, vol. CII, núm. 5. (Dec. 1997). 
Elliot, Michael. A. "Human Rights and the Triumph of the Individual in World" en Cultural Sociology, Exeter, University of Exeter, vol. I, 2007.

Giner, Salvador. "Religión civil”, en REIS, núm. 61, 1993.

Hite, Katherine y Cath, Collins. "Memorial Fragments, Monumental Silences, and Reawakenings in 21st-century Chile", en Millennium: Journal of International Studies, vol. XXXVIII, núm. 2, 2009.

Klein, Kerwin Lee. "On the Emergence of Memory in Historical Discourse", en Representations, núm. 69, 2000.

Lazzara, M. J. "Dos propuestas de conmemoración pública: Londres 38 y el Museo de la Memoria y los Derechos Humanos (Santiago de Chile)", en A Contracorriente, vol. VIII, núm. 3, Spring, 2011.

Montealegre Iturra, Jorge. "El imaginario del Holocausto en la memoria social de las dictaduras latinoamericanas”, en Cultura, lenguaje y representación, vol. X, 2012.

Negro Pavón, D. “El misterio de los derechos humanos”, en Intus-legere, núm. 3, 2000.

Richard, Nelly. "La crítica de la memoria”, en Cuadernos de Literatura, núm. 8, 2002.

Waldman, Gilda. "Chile: la persistencia de las memorias antagónicas", en Política y Cultura, núm. 31, 2009.

\section{Publicaciones en Internet}

Aylwin, Patricio. "Discurso de S.E. el Presidente de la República", en Ortega R., Eugenio y Moreno B., Carolina (comps.). ¿La concertación desconcertada? Santiago de Chile: LOM Eds., 2002, http://www.memoriachilena.cl/archivos2/pdfs/ MC0055348.pdf.

Cádiz, Pablo. Bolivia acusa "veto" por negativa a facilitar Museo de la Memoria para acto con García Linera, http://www.t13.cl/noticia/politica/bolivia-acusa-vetonegativa-facilitar-museo-memoria-acto-garcia-linera.

Manzanero, A. L. y Recio, M. "El recuerdo de hechos traumáticos: exactitud, tipos y características" en Cuadernos de Medicina Forense, vol. XVIII, núm. 1, 2012, http:// scielo.isciii.es/scielo.php?script=sci_arttext\&pid=S1135-76062012000100003.

Morales, Karina. “Incidentes empañan inauguración del Museo de la Memoria”, Emol Nacional, http://www.emol.com/noticias/nacional/2010/01/11/393405/incidentesempanan-inauguracion-del-museo-de-la-memoria.html.

Moulian, Tomás. "Limitaciones de la transición a la democracia en Chile" en Proposiciones, núm. 25, 1994, http://www.sitiosur.cl/publicacionescatalogodetalle. php?PID=3213. 
Sacralización, ritualización y espectáculo en torno al pasado: El Museo de la Memoria...

Piper Shafir, Isabel. Obstinaciones de la memoria: la dictadura militar chilena en las tramas del recuerdo, (tesis doctoral), Universidad Autónoma de Barcelona, 2005, http://www.archivochile.com/tesis/07_ddhh/07ddhh0001.pdf. 